\title{
Analysis and impact of construction environment on the project cost Wenjun Yang, Zhi Dou
}

College of Civil Engineering, Chang'an University, Xi'an 710061, China

Keywords: construction environment ; project cost; set pair analysis; AHP

\begin{abstract}
From the construction environment point of view, the evaluation index system was established, using the set pair analysis method, evaluation on project cost effect model based on the construction environment was built, and an example was given to analyze the factors influencing the construction cost, providing reference basis for engineering cost control.
\end{abstract}

\section{Introduction}

The project is specific to the project construction as the goal and is a one-time job which construction enterprises complete under certain conditions[1]. The project cost refers to the sum of all the costs that enterprise uses for construction and management [2], it reflects the consumption of labor and material of the engineering synthetically.

\section{The evaluation index system of construction environment on project cost}

Reducing cost of the project reasonably is a basic work target in engineering construction. The engineering cost includes indirect costs and direct costs. Indirect cost refers to the total expenditure of construction preparation and management, also including the necessary expenses incurred in engineering construction, such as maintenance costs, material consumption, travel expenses and utilities. Direct cost refers to the cost of the engineering entity in engineering construction and various expenses that in favor of the project entities, which can be included in engineering cost directly. In addition, the construction cycle and the occurrence of material engineering cost are also important factors which have an important impact on the project cost [3]. These cost varies with the construction itself and the internal and external state of the construction enterprise, such as the nature of engineering, construction condition, enterprise technical conditions, the degree of mechanization, construction organization and the lifting of construction materials prices and so on, they all affect project cost directly [4]. Whether the construction scheme is advanced and feasible and whether technical and organizational measures is reasonable determine the level of the project cost to a great extent. Finding out the key influence factors will lay the foundation for us to find ways to reduce project cost. In this paper, from five aspects of the construction organization plan, construction period, construction quality, construction safety and construction site management, construction of evaluation index system of the project cost is established, we can see in table 1 .

Tab.1. The evaluation index system of construction environment on project cost

\begin{tabular}{|c|c|c|}
\hline First class index & Second class index & Third class index \\
\hline \multirow{9}{*}{$\begin{array}{c}\text { construction } \\
\text { environment of } \\
\text { evaluation index } \\
\text { system of the project } \\
\text { cost } A\end{array}$} & \multirow{5}{*}{$\begin{array}{l}\text { the construction } \\
\text { organization plan } C_{1}\end{array}$} & Construction method $\mathrm{x}_{11}$ \\
\hline & & Construction machinery and equipment $\mathrm{x}_{12}$ \\
\hline & & Construction organization $\mathrm{x}_{13}$ \\
\hline & & Construction sequence arrangement $\mathrm{x}_{14}$ \\
\hline & & Site layout $\mathrm{x}_{15}$ \\
\hline & \multirow{4}{*}{ construction period $C_{2}$} & The influence of the relevant units $\mathrm{x}_{21}$ \\
\hline & & The change of construction conditions $\mathrm{x}_{22}$ \\
\hline & & The technical level and error occurred $\mathrm{x}_{23}$ \\
\hline & & The level of construction management $x_{24}$ \\
\hline
\end{tabular}




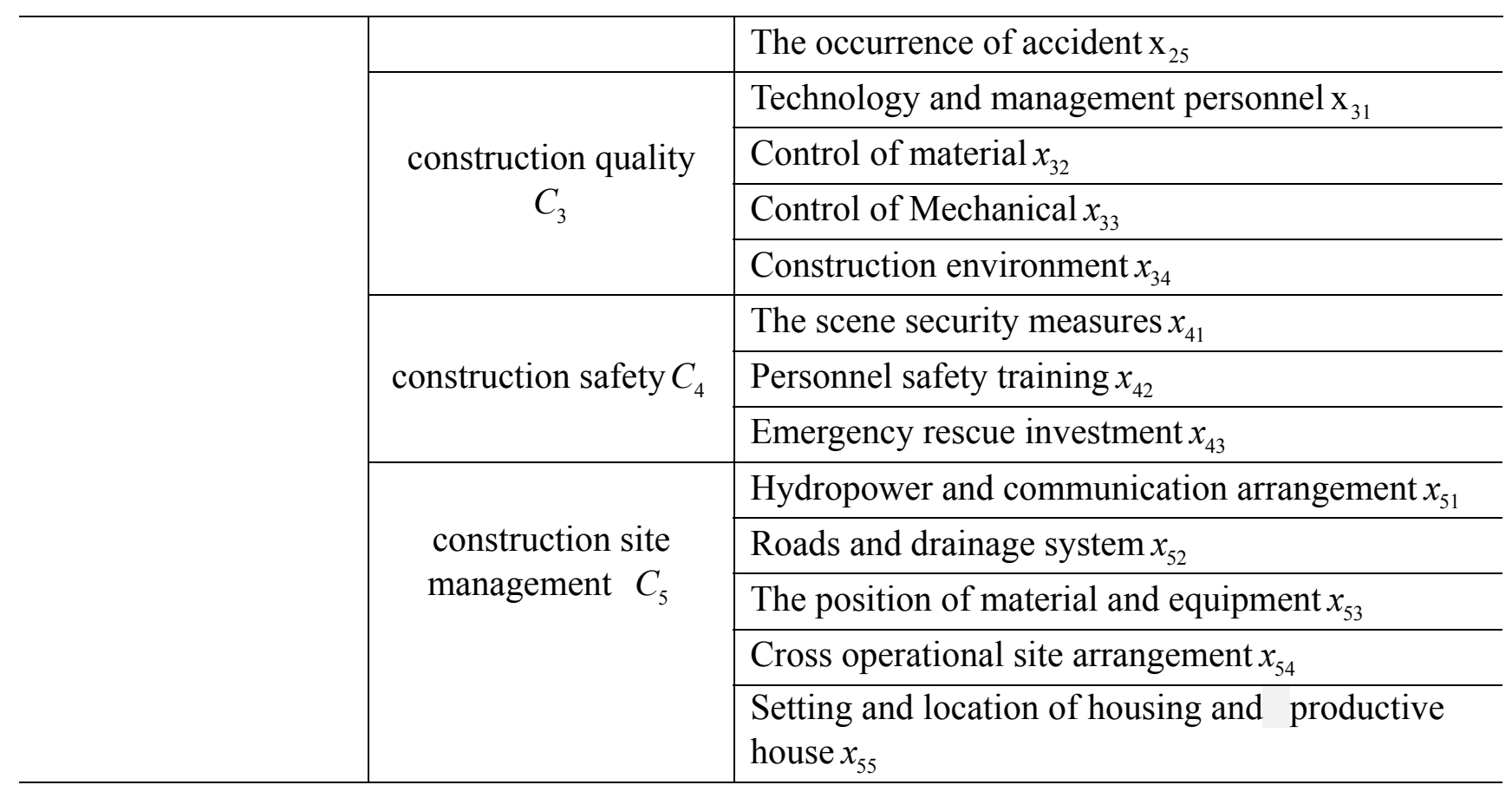

\section{Evaluation model of construction environment on project cost}

\subsection{Evaluation model of the third class index of construction environment on project cost}

Suppose the panel aggregation who participate in the evaluation of construction environmental indicators of the is $D=\left\{d_{1}, d_{2}, \cdots d_{z} \cdots d_{g}\right\}$, the second class evaluation index of construction environment is $C=\left\{C_{1}, C_{2}, \cdots C_{k} \cdots C_{5}\right\}$. The maximum score on each index is $q$ and the score will be higher if the index has more influence on project cost. The third class index of construction environment on project cost is $X=\left\{x_{k 1}, x_{k 2}, \cdots x_{k t} \cdots, x_{\mathrm{ks}}\right\}$. The evaluation matrix which constructed of the Zth groups of the panel on the second level of evaluation indexes of the third level evaluation index is presented in formula (1).

$$
M_{Z}=\left[\begin{array}{cccc}
m_{1 k 1} & m_{1 k 2} & \cdots & m_{1 k t} \\
m_{2 k 1} & m_{2 k 2} & \cdots & m_{2 k t} \\
& & \\
m_{z k 1} & m_{z k 2} & \cdots & m_{z k t}
\end{array}\right] \quad(\mathrm{z}=1,2, \cdots, \mathrm{g} ; \mathrm{k}=1,2, \cdots, 5 ; \mathrm{t}=1,2, \cdots, \mathrm{s})
$$

In formula (1), ${ }^{m_{z k t}}$ represents the value that the Zth groups of the panel on the second level $C_{k}$ of evaluation indexes of the third level evaluation index $x_{\mathrm{kt}}$. When you evaluate the index of construction environment on project cost. The value of the same index will be differ because of individual diversity. According to the IDC thought of the method, $\min \left(m_{z k t}\right)$ represents the minimum value of all the groups of the panel on the $k_{\text {th }}$ of the second level of evaluation indexes

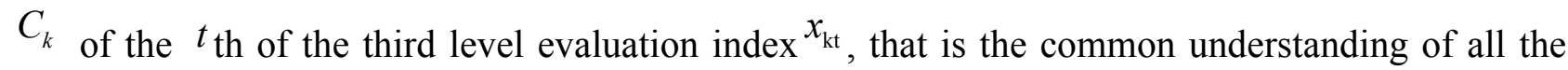
experts group on this evaluation index. $\min \left(m_{z k t}\right) / q$ represents the identity of all the panel on this evaluation index. Likewise, $\max \left(m_{z k t}\right)-\min \left(m_{z k t}\right)$ represents the difference of cognition of all the groups of the panel on this index, $\left(\max \left(m_{z k t}\right)-\min \left(m_{z k t}\right)\right) / q$ represents variability among all the 
panel on this evaluation index, $1-\max \left(m_{z k t}\right) / q$ represents antagonism of all the panel on this evaluation index $[5,6]$.

According to the above analysis, set pair analysis matrix of the second level of evaluation indexes $C_{k}$ of the third level evaluation index $x_{\mathrm{kt}}$ is constructed and presented in formula (2).

$$
\mu_{k}=\left[\mu_{k 1} \mu_{k 2} \cdots \mu_{k t}\right] \quad(\mathrm{k}=1,2, \cdots, \mathrm{h} ; \mathrm{t}=1,2, \cdots, \mathrm{s})
$$

In formula (2), $\mu_{k t}=a_{k t}+b_{k t} i+c_{k t} j, a_{k t}=\min \left(m_{z k t}\right) / q, \quad b_{k t}=\max \left(m_{z k t}\right)-\min \left(m_{z k t}\right) / q$, $c_{k t}=1-a_{k t}-b_{k t}$. i represents coefficient of variability of all the groups of the panel on this index,

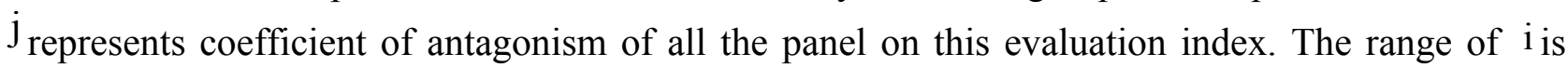

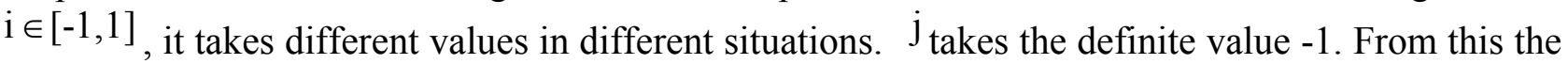
correlation coefficient of all the third level evaluation index are calculated.

\subsection{Determination of the weight of the second class of evaluation index of construction environment on project cost}

(1) Construction of judgment matrix. The meaning of judgment matrix division is presented in Tab.2, each two indexes compare and then construct judgment matrix.

Tab.2. The meaning of judgment matrix division

\begin{tabular}{cc}
\hline division & Have the same importance \\
\hline 1 & The former is a bit more important than the latter \\
5 & The former is obviously more important than the \\
latter
\end{tabular}

reciprocal The degree that the latter is more important than the former

(2) Solution of the weight value. The root mean square method is used as following.

(1) Calculate the geometric average value of all the elements of each row of the matrix, then make them orthogonal, as formula (3) and formula (4) presented.

$$
\begin{gathered}
\overline{w_{i}}=\sqrt[n]{\prod_{j=1}^{n} a_{i j}} \\
w_{i}=\frac{\overline{w_{i}}}{\sum_{j=1}^{n} \overline{w_{j}}}
\end{gathered}
$$

In formula (3) and formula (4), ${ }^{n}$ represents the order of the matrix.

(2) Calculate the maximum eigenvalue of the matrix, as formula (5) presented.

$$
\lambda_{\max }=\frac{1}{n} \sum_{i=1}^{n} \frac{(A W)_{i}}{w_{i}}
$$

(3) Consistency test of the matrix, as formula (6) an formula (7)presented.

$$
\text { C.R. }=\frac{\text { C.I. }}{\text { R.I. }}
$$




$$
\text { C.I. }=\frac{\lambda_{\max }-n}{n-1}
$$

In formula (6) and formula (7), C.I. is the index of consistency test, $n$ is the order of the matrix, $R . I$. is the index of the average random consistency test and its value is presented in Tab.3.

Tab.3. Value of the index of the average random consistency test R.I.

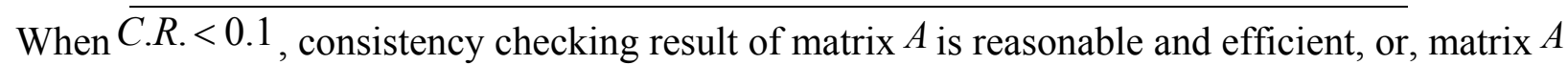

\begin{tabular}{ccccccccccc}
\hline order & 1 & 2 & 3 & 4 & 5 & 6 & 7 & 8 & 9 & 10 \\
\hline R.I. & 0 & 0 & 0.52 & 0.89 & 1.12 & 1.26 & 1.36 & 1.41 & 1.46 & 1.49 \\
\hline
\end{tabular}
should be adjusted until it satisfies the consistency test.

\subsection{Determination of synthesize connection number of the third class of evaluation index of construction environment on project cost}

The synthesize connection number $u_{k t}$ is the product of contact number $\mu_{k t}$ and the weight of the corresponding second class index ${ }^{w_{k}}$. It is presented in formula (8).

$$
u_{k t}=\mu_{k t} \cdot w_{k}(k=1,2, \cdots, 5 ; \mathrm{t}=1,2, \cdots, \mathrm{s})
$$

\section{Example}

There is a project in Xi'an Yanta District that is contracted by a construction units of secondary release in Shanxi Province. According to the actual situation, 5 groups of panels are selected to evaluate the construction environment on impacting construction cost respectively

\subsection{Calculation of connection number of the third class of evaluation index of construction environment on project cost}

First, mark for the third level evaluation index. Using set pair analysis to calculate the connection number of the third class of evaluation index. Take the construction organization plan for example, the other four are similar, so final result of calculation are given only.

The evaluation matrix which constructed by the panel on the construction organization plan of the third level evaluation index is presented as ${ }^{M_{1}}$.

$$
M_{1}=\left[\begin{array}{lllll}
8 & 7 & 8 & 6 & 6 \\
9 & 7 & 6 & 7 & 5 \\
7 & 8 & 5 & 6 & 6 \\
9 & 6 & 8 & 5 & 7 \\
8 & 6 & 6 & 5 & 6
\end{array}\right]
$$

Calculate the connection number of index $x_{1 \mathrm{t}}$ as following:

$\mu_{11}=0.7+0.2 i+0.1 j=0.6+0.2 i$

$\mu_{12}=0.6+0.2 i+0.2 j=0.4+0.2 i$,

$\mu_{13}=0.5+0.3 i+0.2 j=0.3+0.2 i$,

$\mu_{14}=0.5+0.2 i+0.3 j=0.2+0.2 i$,

$\mu_{15}=0.5+0.2 i+0.3 j=0.2+0.2 i$. From this the matrix can be got as following:

$\mu_{1}=[0.6+0.2 i, 0.4+0.2 i, 0.3+0.3 i, 0.2+0.2 i, 0.2+0.2 i]$ 。

By this method, the connection number of construction period $C_{2}$, construction quality $C_{3}$, construction safety $C_{4}$, construction site management $C_{5}$ can be calculated as following:

$\mu_{2}=[0.4+0.2 i, 0.5+0.1 i, 0.5+0.3 i, 0.2+0.2 i, 0.6+0.2 i]$ 


$$
\begin{aligned}
& \mu_{3}=[0.2+0.2 i, 0.4+0.2 i, 0.1+0.2 i, 0.1+0.3 i] \\
& \mu_{4}=[0.4+0.2 i, 0.1+0.3 i, 0.3+0.3 i] \\
& \mu_{5}=[-0.1+0.3 i, 0.2+0.2 i,-0.4+0.2 i, 0.1+0.3 i,-0.2+0.2 i]
\end{aligned}
$$

\subsection{Calculation of the weight of the second class of evaluation index of construction environment on project cost}

According to Tab.2, score the second class of index by the panel, build the judgment matrix and use square root method to calculate eigenvalues and eigenvectors of matrix, and take a disposable test for it, finally obtains the value of the weight of each index, the result is calculated as shown in

\begin{tabular}{|c|c|c|c|c|c|c|c|c|c|}
\hline$U$ & $U_{1}$ & $U_{2}$ & $U_{3}$ & $U_{4}$ & $U_{5}$ & $\begin{array}{c}\text { Product } \\
\text { of a } \\
\text { row }\end{array}$ & $\begin{array}{l}\text { Extract } \\
\text { the } 4^{\text {th }} \\
\text { root }\end{array}$ & $\begin{array}{c}\text { weight } \\
w_{i}\end{array}$ & $\begin{array}{c}\lambda_{\max }=5.0681 \\
\text { C.I. }=0.0170 \\
R I=5\end{array}$ \\
\hline$U_{1}$ & 1 & 2 & 3 & 4 & 5 & 120 & 2.605 & 0.417 & $\begin{array}{l}\text { C.R. } \\
\text { C.I. }\end{array}$ \\
\hline$U_{2}$ & $1 / 2$ & 1 & 2 & 3 & 4 & 12 & 1.644 & 0.263 & $=0.0034<0.1$, \\
\hline$U_{3}$ & $1 / 3$ & $1 / 2$ & 1 & 2 & 3 & 1 & 1 & 0.160 & $\begin{array}{l}\text { it satisfies } \\
\text { the }\end{array}$ \\
\hline$U_{4}$ & $1 / 4$ & $1 / 3$ & $1 / 2$ & 1 & 2 & $1 / 12$ & 0.608 & 0.097 & $\begin{array}{c}\text { the } \\
\text { consistency }\end{array}$ \\
\hline$U_{5}$ & $1 / 5$ & $1 / 4$ & $1 / 3$ & $1 / 2$ & 1 & $1 / 120$ & 0.384 & 0.062 & test. \\
\hline \multicolumn{7}{|c|}{ The total } & 6.241 & 0.999 & \\
\hline
\end{tabular}
Tab.4.

Tab.4. Judgment matrix, weight and disposable test

\subsection{Calculation of synthesize connection number of the third class of evaluation index of construction environment on project cost}

When $i=0$, that is to say, do not consider the otherness that the panel mark the index when select each index. At last, synthesize connection number can be got. Among them, when $u_{k t} \leq 0$ and $u_{k t}=0$, that is to say, the influence of this index to project cost is very small and can be neglected. The final

\begin{tabular}{|c|c|c|c|c|c|c|c|c|c|}
\hline index & weight & $\begin{array}{l}\text { contact } \\
\text { number }\end{array}$ & $\begin{array}{c}\text { synthesize } \\
\text { connection } \\
\text { number }\end{array}$ & ranking & index & weight & $\begin{array}{l}\text { contact } \\
\text { number }\end{array}$ & $\begin{array}{l}\text { synthesize } \\
\text { connection } \\
\text { number }\end{array}$ & ranking \\
\hline $\mathrm{x}_{11}$ & \multirow{5}{*}{0.417} & 0.6 & 0.250 & 1 & $x_{32}$ & \multirow{3}{*}{0.160} & 0.4 & 0.064 & 10 \\
\hline $\mathrm{x}_{12}$ & & 0.4 & 0.167 & 2 & $\mathrm{x}_{33}$ & & 0.1 & 0.016 & 15 \\
\hline $\mathrm{x}_{13}$ & & 0.3 & 0.125 & 6 & $x_{34}$ & & 0.1 & 0.016 & 15 \\
\hline $\mathrm{x}_{14}$ & & 0.2 & 0.083 & 8 & $x_{41}$ & \multirow{3}{*}{0.097} & 0.4 & 0.039 & 12 \\
\hline $\mathrm{x}_{15}$ & & 0.2 & 0.083 & 8 & $x_{42}$ & & 0.1 & 0.001 & 19 \\
\hline $\mathrm{x}_{21}$ & \multirow{5}{*}{0.263} & 0.4 & 0.105 & 7 & $x_{43}$ & & 0.3 & 0.029 & 14 \\
\hline $\mathrm{x}_{22}$ & & 0.5 & 0.132 & 4 & $x_{51}$ & \multirow{5}{*}{0.062} & 0 & 0 & 20 \\
\hline $\mathrm{x}_{23}$ & & 0.5 & 0.132 & 4 & $x_{52}$ & & 0.2 & 0.012 & 17 \\
\hline$x_{24}$ & & 0.2 & 0.053 & 11 & $x_{53}$ & & 0 & 0 & 20 \\
\hline $\mathrm{x}_{25}$ & & 0.6 & 0.158 & 3 & $x_{54}$ & & 0.1 & 0.006 & 18 \\
\hline $\mathbf{x}_{31}$ & 0.160 & 0.2 & 0.032 & 13 & $x_{55}$ & & 0 & 0 & 20 \\
\hline
\end{tabular}
result is presented in Tab.5.

Tab.5. Synthesize connection number and the ranking

According to the Tab.6, we can make a conclusion that construction methods and technical 
measures, construction machinery and equipment, the occurrence of accident have great impact on project cost, while hydropower and communication arrangement, the position of material and equipment, setting and location of housing and productive house have little impact on it. According to the evaluation result, during the construction, more measures should be taken on the elements that have great impact on project cost and proper measures also should be taken on the elements that have less impact on project cost in order to make the project cost in control.

\section{Conclusion}

Project cost control is an important element that project management should control. Using set pair analyses is an effective method to evaluate the elements of construction environment on project cost. When applying this method, building a whole and reasonable index system is of great concern. The value of coefficient of variability ${ }^{i}$ will have an impact on the final result, so when using this method, combine the reality, make a proper value for ${ }^{i}$ to ensure the fairness of the evaluation.

\section{References}

[1] Liu yueying. Technology and management. Beijing: Chemistry Industry Press, 2009(2):44-46.

[2] Hu lilu. Relationship between the construction period and project cost. Railway engineering cost management, 2007(3):15-17.

[3] Ren qun. The influence factors of construction project cost and cost control management method. Manager Journal, 2014(2):345.

[4] Gao yuan. Discussion and analysis of construction safety measures. Value engineer, 2011 (16):88.

[5] Zhao keqin. Set pair analysis and the preliminary application. Zhejiang science and Technology Press: Hangzhou,2000.

[6] Hua yuwen. Supplier selection method of green building under the mode of supply chain management. Journal of Yellow River Conservancy Technical Institute,2007(7):30-32.

[7] Liu liang. Study on the energy consumption of the whole life cycle of urban residential building in Qinghai Province. Chang'an University. 2010,06. 